
\title{
Genetically enhanced food for thought
}

\author{
Edward S. Golub
}

I recently saw an article from an organization called Mothers For Natural Law urging that all genetically engineered food be banned because, " $(\mathrm{G})$ enetic engineering is not some minor biotech development. It is a radical new technology that violates fundamental laws of nature." Scientists, policy makers, and the biotechnology industry have been concerned for at least a decade about the public's growing skepticism of science in general, and biotechnology in particular, and over the past two years of lecturing to the public on science subjects, I have been struck by how often I hear variants of the naturalness argument about genetically engineered food. The problem is not one of abstract philosophy, because a good deal of hope and money is riding on the agbiotechnology industry, and there is ample evidence of the resistance. In the United States, engineered tomatoes are both metaphorically and literally dying on the vine, and demands for cautionary labels on milk from cows treated with engineered growth hormone continue. Polls conducted by the European Union consistently find that people feel there will be more benefit to society from biotechnology than from synthetic food or space exploration, but far less than from solar energy, organ transplantation, or informatics, a fact that may explain why engineered seeds are currently meeting regulatory problems in Europe

In contrast, the public, which is bombarded with news about human genetics, has shown a wary acceptance of biotechnology drugs. But even this must be seen in relation to the fact that one in three US citizens visit practitioners of alternative medicine in addition to their primary care physicians, reflecting an increasing desire for alternative, low-tech approaches along with standard, high-tech medicine. At a deeper level, the Human Genome Project found it prudent to include ethical, legal, and social implications right from the start, showing that the public clearly has a love/hate relationship with biotechnology. The ideas of Mothers for Natural Law may be at an extreme end of the

Edward S. Golub, former professor of biology at Purdue University, and director of research at Ortho Biotech, is the author of The Limits of Medicine: How Science Shapes Our Hope for the Cure which will be released in paperback by the University of Chicago Press in April. $\mathrm{He}$ is currently writing a book on the nonscientific role of science in society (egolub@esga.com). spectrum, but the resistance is not frivolous and must be understood and dealt with if the industry is to fulfill its promise

The conventional wisdom is that the negative attitudes and intransigence toward biotechnology products result merely from fear of technology because of scientific illiteracy, and that the remedy is education. But what passes for science education is usually indoctrination, in which success is measured quantitatively by the number of facts retained, and qualitatively by the expression

\section{It is clear that people can} overcome resistance to technology when the technology meets what are perceived as important unmet social needs.

of a positive attitudes toward technology

If we are serious about educating rather than indoctrinating, and have confidence in our products, we should be teaching the statistics of risk assessment, how scientific truth changes in the light of new facts, and above all, the nature of scientific skepticism. The public would then be able to judge for itself the benefit and safety of products. But by equating scientific literacy with acceptance, we have created a population that must rely on the authority of scientists to tell them the value biotechnology products, and once the credibility of that authority is shaken, the confidence is lost. The heart of the problem is that we are losing our credibility, and while I think that science education should be a very high priority for the good of society, it will not solve the problem of resistance to biotechnology products because the root of the problem goes deeper than scientific understanding.

I suggest that the fundamental basis of the love/hate relationship lies outside the area of the rational, linear thinking of science: It is more a response to the idea of genetically engineered products than to the products themselves. By idea, I do not mean the science behind the technology, I mean the deeper existential and spiritual meaning that technology has in people's lives. Talk of existential and spiritual concerns are alien to scientists and industrialists; it is the soft kind of thinking that is the realm of religion and poetry, and there is nothing in our technological training to prepare us to deal with it. Yet, I suggest that we ignore it at our peril.

Most scientists are not aware that providing this deeper meaning was central to the ascendance of science in determining how we order and understand the world that marked the transition from the medieval to the modern age in the seventeenth century. As scientists, we are taught that science won the battle against superstition and mysticism because it used logical, linear thought that is independent of philosophical and spiritual things. But when science replaced religion as the basis for Western cosmology, it was called the "new philosophy" precisely because it provided more than just a basis for understanding physical facts and the technology for the Industrial Revolution: It provided a framework that gave order to the world and deeper meaning to people's lives. This essentially spiritual function of science began to wane in the nineteenth century as the emphasis turned toward technology, and has all but disappeared at the end of the twentieth century.

The root of the love/hate relationship with technology is that neither linear thinking nor the technology are sufficient to provide what Thomas Kuhn, and more recently, Stuart Kauffman, have called our sense of "at-homeness in the universe." I think we can understand the resistance to agbiotechnology products as a reflection of this need. In societies awash in food, vine-ripe red tomatoes in the dead of winter are an easy target on which to vent an inchoate resistance because they are readily seen as an indulgence at best and a marketing ploy at worst; few beyond Mothers for Natural Law and people at their end of the spectrum would raise strong objections to the use of engineered foods in nonindustrialized countries suffering from famine. It is clear that people can overcome resistance to technology when the technology meets what are perceived as important unmet social needs. By ignoring the nontechnical role that science plays in people's lives we ignore a large part of our function in society.

This is not to say that scientists should become mystical. Far from it; but we must become aware of the fact that the abstract, linear, logical thinking that sustains us both intellectually and spiritually as trained scientists is alien to nonscientists. While we educate the public about science, we can educate ourselves to be more aware of the enormous role that nonscientific factors play in response to science and the technology that comes from it. 